TPeriodica Polytechnica Civil Engineering

62(4), pp. 911-920, 2018

https://doi.org/10.3311/PPci.11605

Creative Commons Attribution (i)

RESEARCH ARTICLE

\section{Numerical Analysis and Strength Evaluation of an Exposed River Crossing Pipeline with Casing Under Flood Load}

\author{
Xiaoben Liu ${ }^{1}$, Hong Zhang ${ }^{1 *}$, Mengying Xia ${ }^{1}$, Yanfei Chen ${ }^{1}$, \\ Kai Wu ${ }^{1}$, Baodong Wang ${ }^{1}$ \\ Received 15 October 2017; Revised 24 March 2018; Accepted 19 April 2018
}

\begin{abstract}
Pipelines in service always experience complicated loadings induced by operational and environmental conditions. Flood is one of the common natural hazard threats for buried steel pipelines. One exposed river crossing X70 gas pipeline induced by flood erosion was used as a prototype for this study. A mechanical model was established considering the field loading conditions. Morison equations were adopted to calculate distributional hydrodynamic loads on spanning pipe caused by flood flow. Nonlinear soil constraint on pipe was considered using discrete nonlinear soil springs. An explicit solution of bending stiffness for pipe segment with casing was derived and applied to the numerical model. The von Mises yield criterion was used as failure criteria of the X70 pipe. Stress behavior of the pipe were analyzed by a rigorous finite element model established by the general-purpose Finite-Element package ABAQUS, with $3 D$ pipe elements and pipe-soil interaction elements simulating pipe and soil constraints on pipe, respectively. Results show that, the pipe is safe at present, as the maximum von Mises stress in pipe with the field parameters is $185.57 \mathrm{MPa}$. The critical flow velocity of the pipe is $5.8 \mathrm{~m} / \mathrm{s}$ with the present spanning length. The critical spanning length of the pipe is $467 \mathrm{~m}$ with the present flow velocity. The failure pipe sections locate at the connection point of the bare pipe and the pipe with casing or the supporting point of the bare pipe on riverbed.
\end{abstract}

\section{Keywords}

finite element analysis, river crossing, buried X70 pipe, flood load, pipe soil interaction

\section{Introduction}

Buried steel pipelines are the most commonly long distance transportation tools for both oil and natural gas resources [1]. Pipelines inevitably need to cross rivers or streams [2]. Selection of pipe crossing methods depends upon site specific criteria, such as water flow, soil conditions and so on. Generally, horizontal directional drilling is the major choice for river crossings where local soil conditions permit the technique. Under the flood wash and erosion of river flow, these embedded pipelines in riverbed may be exposed and become spanning pipes in river. Large stress can be generated in pipe, due to bend deformation caused by the combination effects of flood load and soil constraint. Thus, flood load is one significant threat for pipe integrity.

Extensive researches have been conducted for mechanical analysis of buried pipeline subjected to natural hazards induced environmental loads. Some researchers have focused on stress response of suspended spanning pipes under external loads. Most investigations were carried out with numerical analysis. Wang X. [3] established a simplified finite element model of pipe floated in floods. Chen Y. [4] studied the critical states for suspended span pipe with pipe element based numerical model. Li S. [5] built both pipe elements based and solid continuum elements based finite element model to investigate failure performance of spanning pipe with corrosion defects under flooding load. Ma T. [6] and Yao A. [7] both used rigorous numerical models to analysis critical suspended length of steel pipes, in which shell elements and solid elements were utilized to simulate pipe and soil respectively. Foregoing researches were all nonlinear static analysis, Zhang K. et al. [8] investigated the vibration characteristic of spanning pipe via dynamic analysis. Song B. [9] established a numerical model for stress analysis of a pipeline project at Pembina River crossing in Canada, in which creep deformation of riverbed was considered. Besides the numerical investigations, Wang [2] put some efforts on proposing an analytical model for spanning pipe based on elastic-plastic material property and theory of beam on elastic foundation. The analytical results are more convenient for engineering application.

\footnotetext{
1 College of Mechanical and Transportation Engineering, China University of Petroleum-Beijing, Beijing, 102249, China

* Corresponding author, email: hzhang@cup.edu.cn
} 
A lot of relative literatures are also available for mechanical analysis of buried pipes subjected to permanent ground deformation, in which pipe deforms similarly as the ones under flooding load. Newmark [10] and Kennedy [11] conducted some pioneer analytical analysis for buried onshore steel pipe under active fault movements, in which pipe was assumed to behave as cable. Significant improvement on these simplified methods were carried out by Karamitros [12, 13]. He used elastic beam theory to analyze the bending deformation of pipe with linear hardening property at fault crossing. An equivalent bending stiffness was derived making strain results of this model accurate, even when pipe has come into large deformation without sectional ovalization. Based on the main scope of this method, Trifonov et al $[14,15]$ conducted further elastoplastic analysis of steel pipe under fault displacement considering operation load. Similar works were also conducted by Zhang L. [16, 17, 18] on both onshore and offshore buried pipelines under active fault or landslide displacements.

Besides the analytical models mentioned above, both numerical and experimental methods were also widely used for pipe performance under environmental loads. Roudsari [19] studied urban buried GRP pipes under both wave propagation and landslide effects using finite element model with soil constrains on pipe simulated as discrete nonlinear soil springs. Oskouei [20] used similar numerical methods to investigate seismic behavior of steel pipes under wave propagation effects.

Liu [21, 22, 23, 24, 40] conducted a series of numerical analysis for buried high strength gas pipeline with emphasis on their strain demand under fault displacements. Saberi [25] proposed a semi analytical model for strain prediction of elbow by combined use of finite element method and nonlinear regression method. Joshi [26], Uckan [27], and Kaya [28] focused on the failure behaviors of buried pipes at fault crossing based on different criteria. Melissianos [29, 30] conducted performance assessment on buried steel pipe at fault crossing through probability analysis. Kainat [31] studied effects of pipe geometric imperfections on pipe buckling behavior under ground induced compression load.

There were also some valuable experiments on pipe under natural hazard loads recently. Jalali $[32,33]$ performed full scale experiment on buried PE and steel pipes under reverse fault displacemnt. Both global and local failure phenomenon were found. O'Rourke studied pipe-soil interation of pipe at fault crossings and the pipe strain response also with a full scale experiment [34]. Melissianos [35] evaluated performance of pipe systems with flexible joints numerically and experimentally, which provides some references on control measures on pipe under hazard loads. Most of all, these few experimental results provides possible data for numerical model calibration.

In general, the listed researches above provide good references for strength analysis of pipe under natural hazard loads, but all of them consider the pipe as a bare pipe, which limit their application on some actual engineering cases that pipe structures are complicated, as the one we faced in this study. Thus a comprehensive investigation was conducted in this study to analysis stress behavior of a spanning pipe with casing under flow load induced by flood erosion. An accurate mechanical model was established according to the field investigation data. Stress in pipe was calculated by a rigorous finite element model coded by general purpose FE solver ABAQUS, in which pipe and soil constraints on pipe were simulated by three dimensional pipe elements and pipe soil interaction elements, separately. Effects of casing on pipe bending deformation under external load was considered reasonably using a demonstrated equivalent bending stiffness. A stress based failure criterion was adopted for safety assessment on pipe. With the proposed numerical model, stress distributions in pipe were studied in detail, and critical flood flow velocity and pipe spanning length were predicted via parametric analysis finally.

\section{Problem description}

During the flood season in 2017 of Irrawaddy River, the largest river in Burma, western riverbed at the crossing position of one X70 steel gas pipeline was eroded seriously leading pipe free spanning at bottom of the Irrawaddy River. The exposed pipe component is under various loadings due to both operational and environmental conditions. Large stress shall be accumulated under these loadings in the potential of leading to failure in pipe, which worries the pipeline operator.

The basic operation parameters of this gas pipeline are as follows. It is a typical longitudinal submerged arc welded X70 pipe, with yield strength of $485 \mathrm{MPa}$. The pipe diameter and wall thickness are $1016 \mathrm{~mm}$ and $26.62 \mathrm{~mm}$, respectively. The operating pressure was initially set to be $10 \mathrm{MPa}$, but the monitoring results shows the actual pipe internal pressure was 9.1 MPa. According to the field investigation reports, free spanning pipe length due to flood erosion was $70 \mathrm{~m}$ in total at present. The water velocity at the crossing position was about $2 \mathrm{~m} / \mathrm{s}$. The western $45 \mathrm{~m}$ long spanning pipe was fixed in a casing, whose diameter and wall thickness are $1860 \mathrm{~mm}$ and $30 \mathrm{~mm}$, respectively. This entire casing is $97 \mathrm{~m}$ long, with the remaining $52 \mathrm{~m}$ long segment buried in the western embankment of the river. From the geological investigation results, strata of the western riverbed, are sandstone, sandy conglomerate, medium and silver sand in order from bottom to the top.

\section{Basic theory and method \\ 3.1 Mechanical model for pipe with casing subjected to flood load}

Based on the geometrical and load condition from field investigation, mechanical model of spanning pipe with casing under flood load can be established as plotted in Fig. 1. In this model, the central pipe segment CE $(70 \mathrm{~m})$ is under flood load, buoyancy load and gravity load. Under these loads in 


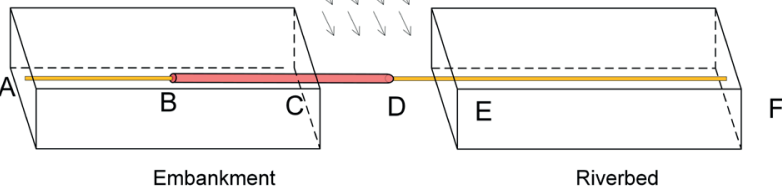

Fig. 1 Sketch of mechanical model for buried X70 gas pipe with casing under flood load

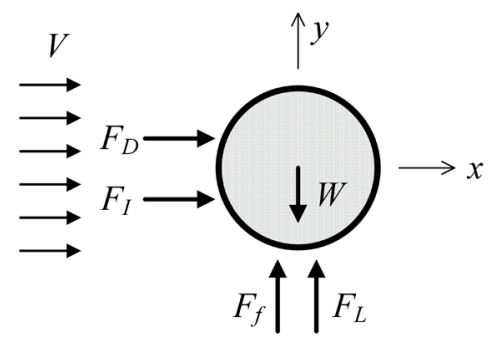

Fig. 2 Load components of pipe sectional forces subjected to flood flow

horizontal and vertical directions, pipe will have three dimensional deformation. Pipe segment BD (97 m) is fixed in casing, its bending stiffness will be larger than bare pipe segments, which will affect its bending deformation and stress distribution. Pipe segment BD is also composed of two segments. Segment BC $(52 \mathrm{~m})$ is buried in the western embankment, while segment $C D(45 \mathrm{~m})$ is spanning in the flood. Pipe segment AB (200 m) and EF $(200 \mathrm{~m})$ are adjacent pipes of the spanning pipe, which are buried in medium sand of the western embankment and riverbed, respectively. Thus, when segment $\mathrm{CE}$ is deformed under flood load, soil resistant force will be applied on segment AC and EF. The mechanical model can be simulated by the finite element model described in Section 4. In the following paragraphs of this section, relative theories about this mechanical model are elaborated primarily.

\subsection{Distribution load applied on pipe structures in flood}

Load conditions of pipe in flood is complicated. A pipe under general flow will under hydrodynamic load, gravity and buoyancy load, as shown in Fig. 2.

The Morison equation is commonly adopted to calculate the sectional hydrodynamic forces on tube or pipe structures under flow, which is a combination of an inertial term $F_{I}$ and a drag term $F_{D}$ in horizontal direction and a lift term $F_{L}$ in the vertical direction [36].

$$
\begin{gathered}
F_{D}=0.5 \rho_{w} D C_{D} v_{e}^{2} \\
F_{I}=0.25 \rho_{w} \pi D^{2} C_{M}(d v / d T) \\
F_{L}=0.5 \rho_{w} D C_{L} v_{e}^{2}
\end{gathered}
$$

where, $\rho_{w}$ is the water density, $\mathrm{kg} / \mathrm{m}^{3} ; D$ is the pipe (or casing) outer diameter, $\mathrm{m} ; v_{e}$ is flood velocity, $\mathrm{m} / \mathrm{s} ; C_{M}$ is the constant mass coefficient; $C_{D}$ is the constant drag coefficient
Table 1 Referred hydrodynamic coefficents for Morison equation

\begin{tabular}{lccccc}
\hline $\operatorname{Re}\left(\times 10^{5}\right)$ & $<0.5$ & $0.5 \sim 1$ & $1 \sim 2.5$ & $2.5 \sim 5$ & $>5$ \\
\hline$C_{D}$ & 1.3 & 1.2 & $1.53-\operatorname{Re} /\left(3 \times 10^{5}\right)$ & 0.7 & 0.7 \\
$C_{L}$ & 1.5 & 1.0 & $1.2-\operatorname{Re} /\left(3 \times 10^{5}\right)$ & 0.7 & 0.7 \\
$C_{M}$ & 2 & 2 & 2 & $2.5-\operatorname{Re} /\left(5 \times 10^{5}\right)$ & 1.5 \\
\hline
\end{tabular}

and $C_{L}$ is lift coefficient. Referred coefficients for the Morison equation were listed in Table $1[2,36]$, in which $R e$ is the Reynolds number.

The sectional buoyancy force and sectional gravity force for bare pipe can be calculated as follows:

$$
\begin{gathered}
F_{b P i p e}^{f}=0.25 \rho_{w} g \pi D^{2} \\
W_{b P i p e}=\pi g\left[\rho_{P} D t+\rho_{0}(0.5 D-t)^{2}\right]
\end{gathered}
$$

where, $\rho_{P}$ is the pipe steel density, $\mathrm{kg} / \mathrm{m}^{3} ; \rho_{0}$ is the gas density, $\mathrm{kg} / \mathrm{m}^{3} ; t$ is the pipe wall thickness, $\mathrm{m} ; \mathrm{g}$ is gravity acceleration, $\mathrm{m} / \mathrm{s}^{2}$.

While for pipe fixed in casing, the sectional buoyancy force and sectional gravity force can be calculated as follows:

$$
\begin{gathered}
F_{\text {casing }}^{f}=0.25 \rho_{w} g \pi D_{\text {out }}^{2} \\
W_{\text {casing }}=\pi g\left[\rho_{P} D t+\rho_{0}(0.5 D-t)^{2}+\rho_{P} D_{\text {out }} t_{\text {out }}\right. \\
\left.+0.5 \rho_{s}\left(D_{\text {out }}+D-2 t_{\text {out }}\right)\left(D_{\text {out }}-D-2 t_{\text {out }}\right)\right]
\end{gathered}
$$

where, $\rho_{s}$ is the caky bentonite mud density, $\mathrm{kg} / \mathrm{m}^{3} ; t_{\text {out }}$ is the casing wall thickness, $\mathrm{m} ; D_{\text {out }}$ is the casing outer diameter, $\mathrm{m}$;

\subsection{Soil constraint on pipe}

The surrounding soil constrain a pipe's displacement, if a relative displacement occurs between them [37]. Based on validated numerical and experimental investigations, ASCEALA Guideline 2001 suggests that, constraints of soil on pipe can be considered as nonlinear soil springs on pipe in three directions, as shown in Fig. 3 [38]. Thus, in this study, soil resistant force on the buried X70 gas pipe is also described using these nonlinear springs which can be realized by the three-dimensional 4-node pipe-soil interaction elements (PSI 34) developed by ABAQUS.

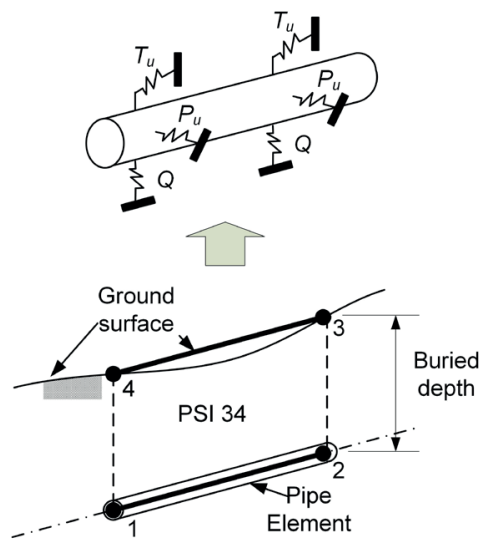

Fig. 3 Soil springs simulating soil constraint on pipe 
Relationships between the soil resistant forces and the corresponding displacements for the nonlinear soil springs in lateral, axial, and vertical directions are illustrated, respectively, in Fig. 4. The parameters $P_{u}, T_{u}$, and $Q_{u}\left(Q_{d}\right)$ represent the maximum soil resistant forces per unit length of pipes, while $\Delta p$, $\Delta t$, and $\Delta q_{u}\left(\Delta q_{d}\right)$ represent the relative soil displacements in three directions, respectively. The values of the above-mentioned maximum soil resistant forces and relative displacement parameters can be readily calculated by the equations from ASCE-ALA Guideline 2005 [38], which are also introduced as follows.

The maximum axial soil resistant force per unit length of pipe that can be transmitted to the pipe is:

$$
T_{u}=\pi D \alpha c+0.5 \pi D H \gamma\left(1+K_{0}\right) \tan (f \phi)
$$

where, $D$ is the pipe diameter, $c$ is the soil cohesion representative, $H$ is the depth of the soil from the ground surface to the center of the pipe, $\gamma$ is the effective unit weight of the soil, $K_{0}$ is the coefficient of the lateral soil pressure at rest, and $f$ is a reduction factor that depends on the outer-surface characteristics and the hardness of the pipe. $\phi$ is the internal friction angle of the soil. $\alpha$ is the adhesion factor.

The relative soil displacement for axial soil spring is:

$$
\Delta t= \begin{cases}3 \mathrm{~mm} & \text { for dense sand } \\ 5 \mathrm{~mm} & \text { for loose sand } \\ 8 \mathrm{~mm} & \text { for stiff clay } \\ 10 \mathrm{~mm} & \text { for stiff clay }\end{cases}
$$

The maximum lateral soil resistant force per unit length of the pipe is:

$$
P_{u}=N_{c h} c D+N_{q h} \gamma H D
$$

where, $N_{c h}$ is the horizontal bearing capacity factor for clay ( 0 for $c=0$ ) and $N_{q h}$ is the horizontal bearing capacity factor for sand ( 0 for $\phi=0^{\circ}$ ). According to the ALA Guideline (2001), the parameters $N_{c h}$ and $N_{q h}$ are functions of the soil friction angle $(\phi)$ and the dimensionless pipe depth $(H / D)$.

The relative soil displacement for lateral soil spring is:

$$
\Delta p=0.04\left(H+\frac{1}{2} D\right)
$$

The maximum vertical soil uplift resistant force per unit length of the pipe is:

$$
Q_{u}=N_{c v} c D+N_{q v} \gamma H D
$$

where $N_{c v}$ is the vertical uplift factor for clay $(0$ for $c=0)$ and $N_{q v}$ is the vertical uplift factor for sand $\left(0\right.$ for $\left.\phi=0^{\circ}\right)$. According to the ALA Guideline (2001), the parameters $N_{c v}$ and $N_{q v}$ are functions of the soil friction angle $(\phi)$ and the dimensionless pipe depth $(H / D)$.

The relative soil displacement for vertical uplift soil spring is:

$$
\Delta q_{u}= \begin{cases}0.01 H \text { to } 0.02 H & \text { for dense to loose sands } \\ 0.1 H \text { to } 0.2 H & \text { for stiff to soft clays }\end{cases}
$$

The maximum vertical soil bearing resistant force per unit length of the pipe is:

$$
Q_{d}=N_{c} c D+N_{q} \gamma H D+0.5 N_{\gamma} \gamma D^{2}
$$

where, $N_{c}, N_{q}$ and $N_{\gamma}$ are the bearing capacity factors, which can be further calculated according to the ALA Guideline(2001) [38].

The relative soil displacement for vertical bearing soil spring is:

$$
\Delta q_{u}= \begin{cases}0.1 D & \text { for grannulr soils } \\ 0.2 D & \text { for cohensive soils }\end{cases}
$$

For the case in presented study, pipe is buried in medium sand with a cohesive stress of $10 \mathrm{kPa}$, a friction angle of $40^{\circ}$, and an effective unit weight of $20 \mathrm{kN} / \mathrm{m}^{3}$. Thus soil spring parameter values can be obtained as listed in Table 2 .

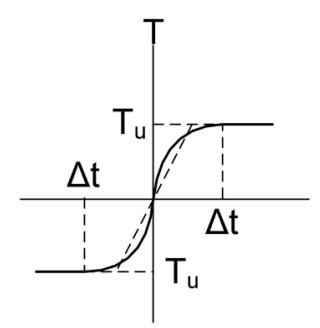

(axial)

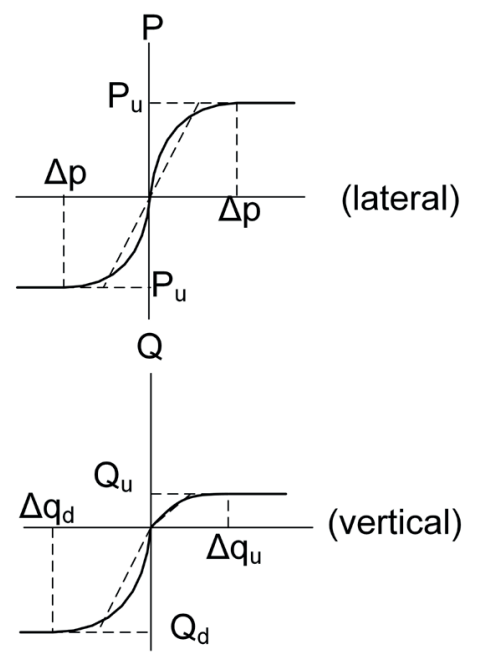

Fig. 4 Relationships of soil resistant forces via pipe soil relative displacements

Table 2 Nonlinear soil spring parameters in presented study

\begin{tabular}{lcccc}
\hline & $\begin{array}{c}\text { Axial } \\
\text { soil spring }\end{array}$ & $\begin{array}{c}\text { Lateral } \\
\text { soil spring }\end{array}$ & $\begin{array}{c}\text { Vertical } \\
\text { bearing } \\
\text { soil spring }\end{array}$ & $\begin{array}{c}\text { Vertical } \\
\text { uplift soil } \\
\text { spring }\end{array}$ \\
\hline $\begin{array}{l}\text { Max soil resistant } \\
\text { force }(\mathrm{kN} / \mathrm{m})\end{array}$ & 71 & 653 & 112 & 4509 \\
$\begin{array}{l}\text { Relative } \\
\text { displacement }(\mathrm{mm})\end{array}$ & 3 & 100 & 30 & 101.6 \\
\hline
\end{tabular}




\subsection{Analytical solution of bending stiffness of pipe with casing}

For the investigated pipe has two pipe sections, i.e. bare pipe and pipe fixed in casing. In this section, bending stiffness of pipe segment fixed in casing is calculated analytically. For the pipe with casing, caky bentonite mud fill the circumlunar space between pipe and casing, making its bending stiffness strengthened than bare pipe. To make analytical solution tractable, plane deformation assumption is adopted here.

Fig. 5 shows the profile of pipe fixed in casing. Based on beam theory, moment in pipe can be integrated by the internal stresses in pipe section:

$$
M=\int \sigma \mathrm{d} A y=\int_{0}^{2 \pi} \int_{r_{1}}^{r_{4}} \sigma \sin \theta r^{2} \mathrm{~d} r \mathrm{~d} \theta
$$

Based on linear elastic material model, one can obtained that:

$$
\begin{aligned}
& M=\int_{0}^{2 \pi} \int_{r_{1}}^{r_{2}} E_{1} \mu \sin \theta r^{2} \mathrm{~d} r \mathrm{~d} \theta+\int_{0}^{2 \pi} \int_{r_{2}}^{r_{3}} E_{2} \mu \sin \theta r^{2} \mathrm{~d} r \mathrm{~d} \theta \\
& +\int_{0}^{2 \pi} \int_{r_{3}}^{r_{4}} E_{1} \mu \sin \theta r^{2} \mathrm{~d} r \mathrm{~d} \theta
\end{aligned}
$$

where, $E_{1}$ is the Young's modulus of pipe steel, MPa; $E_{2}$ is the Young's modulus of the caky bentonite mud between pipe and casing, $\mathrm{MPa} ; r_{1}$ is inner radius of pipe, $\mathrm{m} ; r_{2}$ is outer radius of pipe, $\mathrm{m} ; r_{3}$ is inner radius of casing, $\mathrm{m} ; r_{4}$ is outer radius of casing, $\mathrm{m}$.

According to plane deformation assumption of pipe section, bending strain can be obtained as:

$$
\varepsilon=r \sin \theta / \rho
$$

where, $\rho$ is the radius of curvature of bending pipe, $\mathrm{m}$.

So, bending moment can be further calculated as:

$$
\begin{aligned}
& M=\int_{0}^{2 \pi} \int_{r_{1}}^{r_{2}} \frac{E_{1}}{\rho} \sin ^{2} \theta r^{3} \mathrm{~d} r \mathrm{~d} \theta+\int_{0}^{2 \pi} \int_{r_{2}}^{r_{3}} \frac{E_{2}}{\rho} \sin ^{2} \theta r^{3} \mathrm{~d} r \mathrm{~d} \theta \\
& +\int_{0}^{2 \pi} \int_{r_{3}}^{r_{4}} \frac{E_{1}}{\rho} \sin ^{2} \theta r^{3} \mathrm{~d} r \mathrm{~d} \theta
\end{aligned}
$$

Thus, bending stiffness of pipe with casing can be finally derived:

$$
M p=\frac{1}{4}\left[E_{1} \pi\left(r_{2}^{4}-r_{1}^{4}\right)+E_{2} \pi\left(r_{3}^{4}-r_{2}^{4}\right)+E_{1} \pi\left(r_{4}^{4}-r_{3}^{4}\right)\right]
$$

Based on this derived bending stiffness, we can remove casing in physical modeling and use this derived equivalent stiffness by Equ. 20 to calculate axial strain of pipe in the numerical model in Section 4.

To validate the analytical result of bending stiffness, a simple numerical investigation was conducted here. Finite element model is illustrated in Fig. 6. In the analysis a $10 \mathrm{~m}$ long pipe was considered. Two models were established. For the first one, the actual pipe with casing was modeled. For the second one, only the inner pipe was modeled, but its bending stiffness was revised to be the same as the pipe with casing

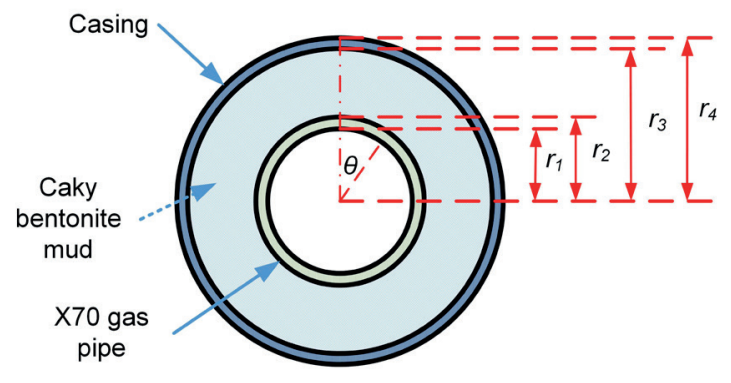

Fig. 5 Cross profile of the $\mathrm{X} 70$ gas pipe fixed in casing

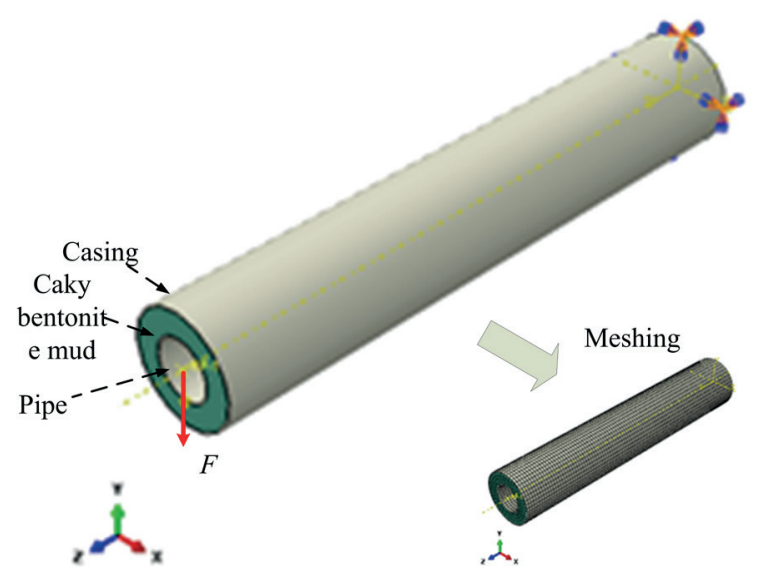

Fig. 6 Numerical model for bending deformation of pipe with casing

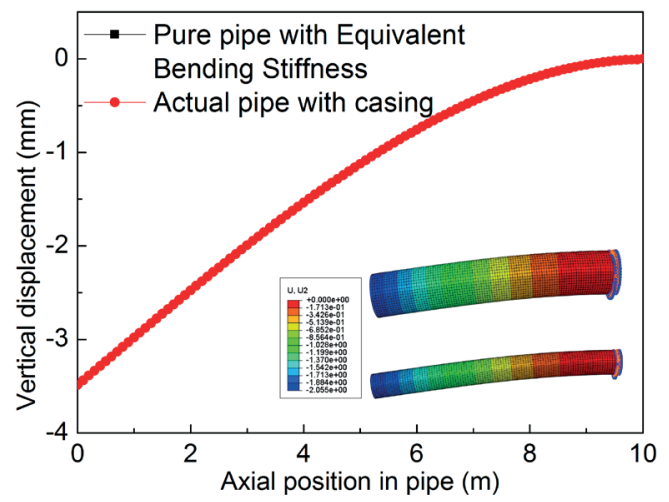

Fig. 7 Comparison results for pipe with casing and bare pipe with equivalent bending stiffness

calculated by Equ. 20. Fig. 7 shows the comparison results of pipe responses of these two models, reflecting that negligible difference exists between them. Thus this method was utilized in the numerical model in Section 4 to consider effects of casing on pipe's bending deformation.

\subsection{Von Mises yield criterion}

In the presented investigation, a stress based failure criterion is adopted. The X70 pipe steel can be described by a $J_{2}$ metal plasticity model with isotropic hardening [39]. Thus, the pipe become yield when maximum von Mises stress $\sigma_{\text {Mises }}$ in pipe reaches yield strength $\sigma_{\text {yeild }}$.

$$
\sigma_{\text {Mises }}=\sqrt{\frac{1}{2}\left[\left(\sigma_{1}-\sigma_{2}\right)^{2}+\left(\sigma_{1}-\sigma_{3}\right)^{2}+\left(\sigma_{2}-\sigma_{3}\right)^{2}\right]}
$$

where, $\sigma_{1,2,3}$ are three principal stresses, MPa. 
As a typical thin wall structure, the three principal stresses in pipe are the axial stress $\sigma_{a x}$, radial stress $\sigma_{r a}$ and hoop stress $\sigma_{h o}$, respectively, which makes Equ. 21 transformed into:

$$
\sigma_{\text {Mises }}=\sqrt{\frac{1}{2}\left[\left(\sigma_{h o}-\sigma_{a x}\right)^{2}+\left(\sigma_{h o}-\sigma_{r a}\right)^{2}+\left(\sigma_{a x}-\sigma_{r a}\right)^{2}\right]}
$$

\section{Numerical analysis model}

To investigate the stress behavior of the X70 pipe described in Section 3.1. A refined finite element model was established by the general code package ABAQUS [41]. The entire pipe was set to be $522 \mathrm{~m}$, as explained in Section 3.1. The pipe was modeled by 3D pipe elements (PIPE 31), with different bending stiffness assigned to different pipe segments. Pipe segment BD was assigned by equivalent bending stiffness derived in Section 3.4. A fine mesh with element length of $0.1 \mathrm{~m}$ was utilized for segment $\mathrm{BE}$ to investigate the accurate mechanical response of pipe under flood loading. While a coarse mesh with element length of $1 \mathrm{~m}$ was used for the adjacent pipes, since they are just considered as boundaries of the model. The same amount of PSI elements, corresponding to pipe elements in Segment AC and EF were used to model soil constraints on pipe (Fig. 8). In the numerical analysis, two loading steps were set. In the first pipe pressure loading step, operating pressure was applied on the entire pipe. In the second step, distribution load derived by Section 3.2 was applied on pipe segment CE. The non-linear Newton-Raphson algorithm were utilized to ensure the convergence of the problem.

\section{Results and discussion}

In this section, strength verification of the exposed X70 steel gas pipeline at Irrawaddy River crossing was performed by the established numerical model first. Parametric analysis was also conducted then to predict the critical flow velocity and spanning length for pipe failure based on the von Mises yield criterion.

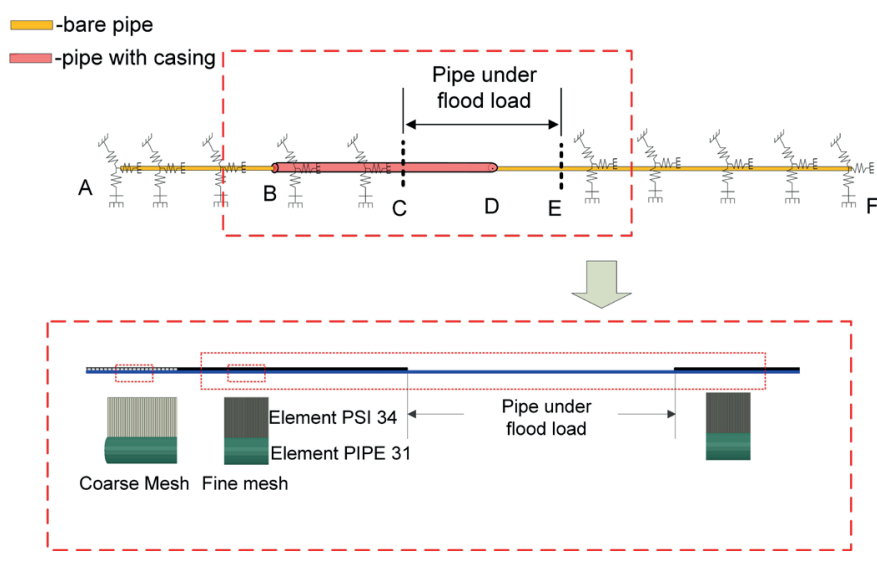

Fig. 8 Sketch of the finite element model

\subsection{Stress analysis and safety evaluation of the X70 pipe under flood load}

For pressurized gas pipe, the radial stress of pipe is negligible, i.e. $\sigma_{r a}=0$. According to the given parameters, the hoop stress $\sigma_{h o}$ can be calculated easily as follows:

$$
\sigma_{\text {ho }}=p D_{\text {in }} /(2 t)=164.5 \mathrm{MPa}
$$

The axial stress oax can be calculated by Hooke's law, as expressed below:

$$
\sigma_{a x}=E \varepsilon_{a x}+v p D_{i n} /(2 t)
$$

where, $\varepsilon_{a x}$ is the axial strain, which can be obtained by the finite element model; $E$ is Young's modulus, $E=210 \mathrm{GPa}$; $v$ is Possion's ratio, $v=0.3$.

From geometrical and flood parameters described in Section 2, distribution sectional forces on spanning pipe segments under $2 \mathrm{~m} / \mathrm{s}$ flow impact can be calculated as listed in Table 3. Using the finite element model, axial strain in pipe can be obtained, as illustrated in Fig. 9. Results show that pipe deforms both in vertical and horizontal planes. Under this circumstance, pipe mainly deforms as bending, making symmetrical longitudinal strain exists at outer pipe surfaces both vertically and horizontally. And it can be further found that, the maximum tensile and compressive strain occurs at the connection point of the bare pipe and pipe with casing (Point D in Fig. 8). This is caused by the sharp bending stiffness variation at this point. Partially peak values also occur at the supporting points of the western embankment and the riverbed, i.e., Point $\mathrm{C}$ and Point $\mathrm{E}$ in Fig. 8, which is caused by the local bending strain induced by soil constraints. The longitudinal strain contour of spring line facing flow is also shown in Fig. 10.

Table 3 Distribution sectional forces on spanning pipe segments

\begin{tabular}{lcccc}
\hline & \multicolumn{2}{c}{ Pipe segment CD } & \multicolumn{2}{c}{ Pipe segment DE } \\
& Horizontal & Vertical & Horizontal & Vertical \\
& component & component & component & component \\
& $(\mathrm{N} / \mathrm{m})$ & $(\mathrm{N} / \mathrm{m})$ & $(\mathrm{N} / \mathrm{m})$ & $(\mathrm{N} / \mathrm{m})$ \\
\hline Value & 7882 & 4413 & 3113 & 4479 \\
\hline
\end{tabular}

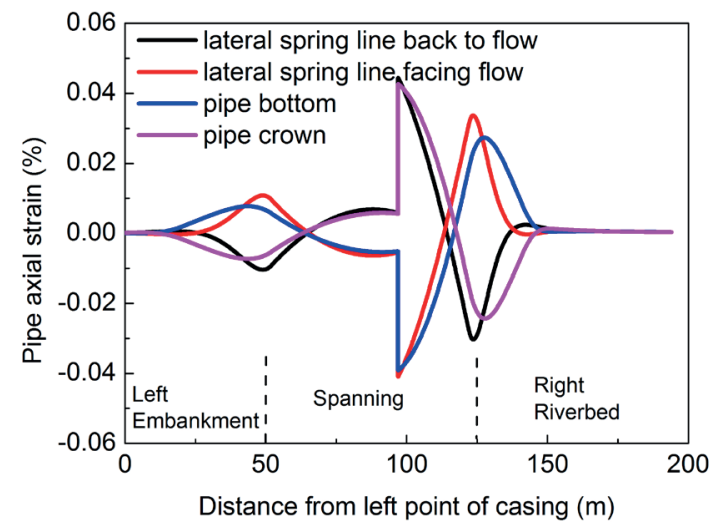

Fig. 9 Longitudinal strain distribution along pipe axis 


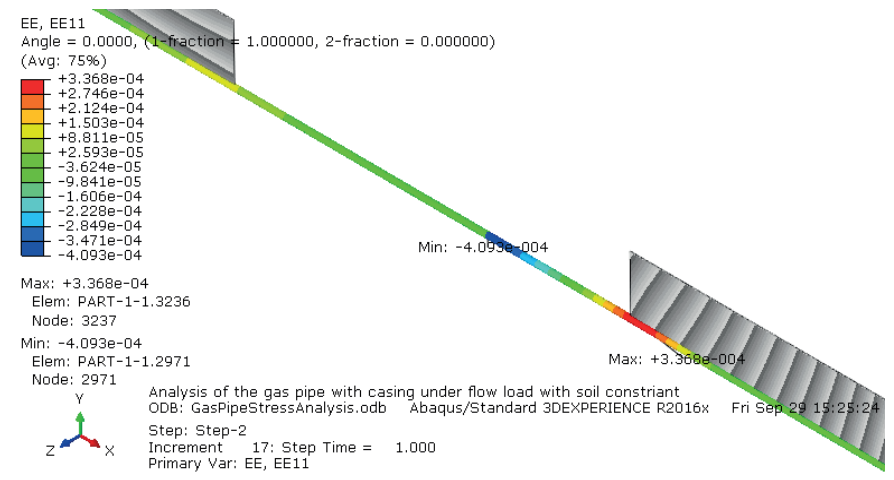

Fig. 10 Longitudinal strain contour of lateral spring line facing flow

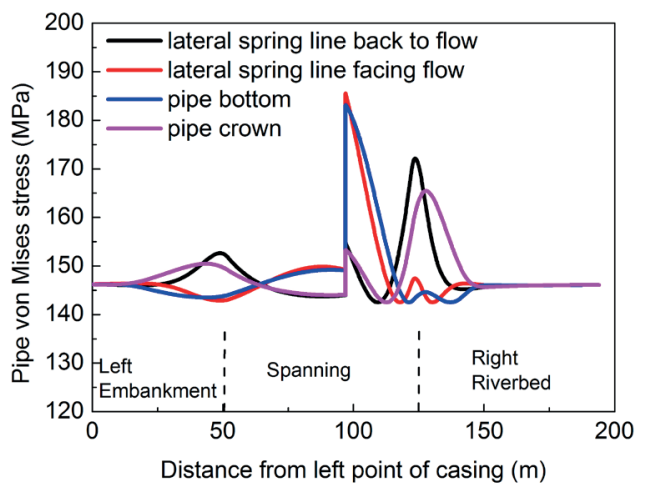

Fig. 11 Von Mises stress distribution along pipe axis

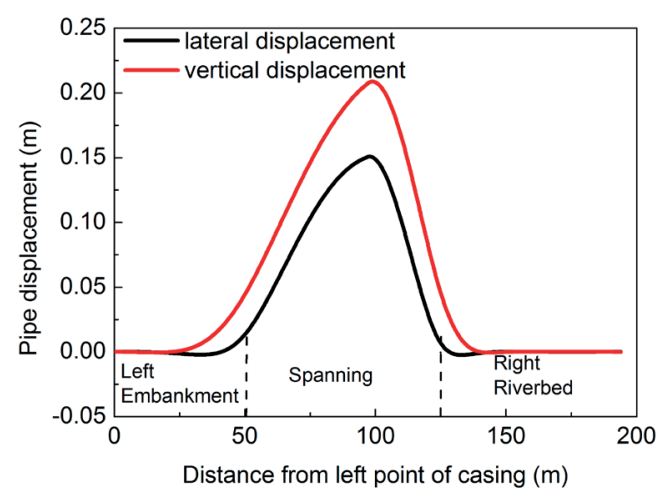

(a) Pipe displacement distribution along pipe axis
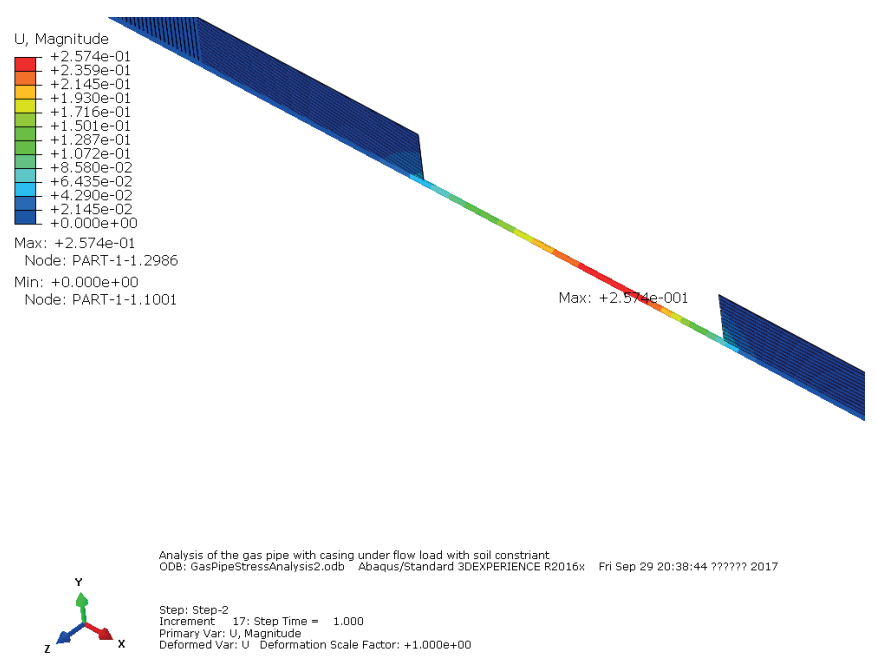

(b) Spatial displacement contour results

Fig. 12 Displacement results for spanning pipe under $2 \mathrm{~m} / \mathrm{s}$ flood load
Based on the strain results and Equ. 22-24, von Mises stresses in pipe can be further derived, as illustrated in Fig. 11. Comparing Fig. 11 with Fig. 9 and 10, it can be derived that, similar with the longitudinal strain results, von Mises stress concentrates at the connection point of the bare pipe and pipe fixed in casing. The peak von Mises stress is $185.57 \mathrm{MPa}$, locating at the spring line facing flow.

Fig. 12 plots the pipe displacements in both vertical and horizontal plane. The maximum pipe displacements in both directions occur in the spanning bare pipe, 23.5 meters away from the soil supporting point at riverbed (Point E in Fig. 8). And the peak spatial displacement equals $0.257 \mathrm{~m}$, which is relatively small comparing with the entire spanning pipe length 70 meters.

In general, under this loading condition, the maximum von Mises stress in pipe is $185.57 \mathrm{MPa}$, which is much less than the yeid strength of X70 line pipe steel $(485 \mathrm{MPa})$. Thus, the pipe is safe under $2 \mathrm{~m} / \mathrm{s}$ flood impact.

\subsection{Critical flow velocity for pipe failure}

Based on the established numerical model, effect of flow velocity on von Mises stress in pipe is investigated in detail. Fig. 13 illustrates trends of maximum von Mises stresses at different positions in pipe section with flow velocity $v_{e}$. The red dashed line is the upper bound of all lines, which makes it to be the maximum von Mises stress in pipe section. Obviously, with increase of $v_{e}$, von Mises stresses at all positions in the pipe section increase.

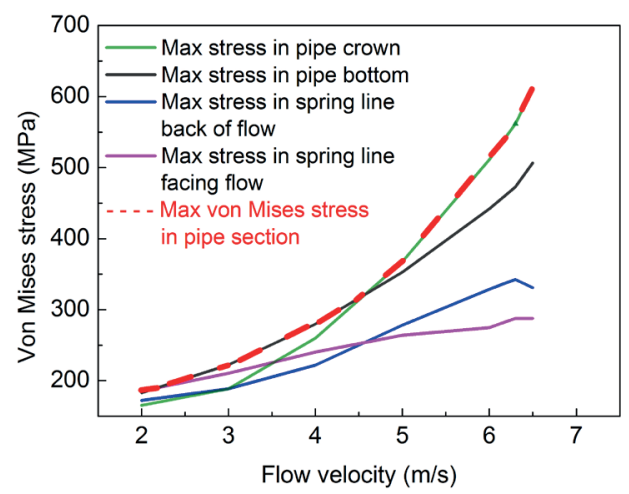

Fig. 13 Trends of maximum stresses in pipe with flood flow velocity

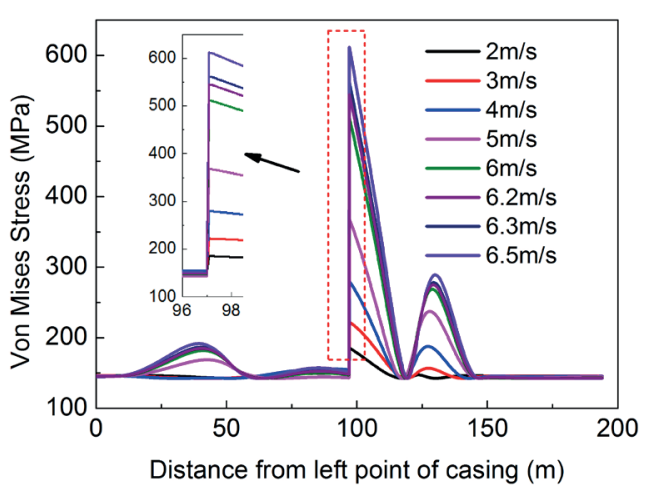

Fig. 14 Distribution of von Mises stress along pipe at different flow velocity 


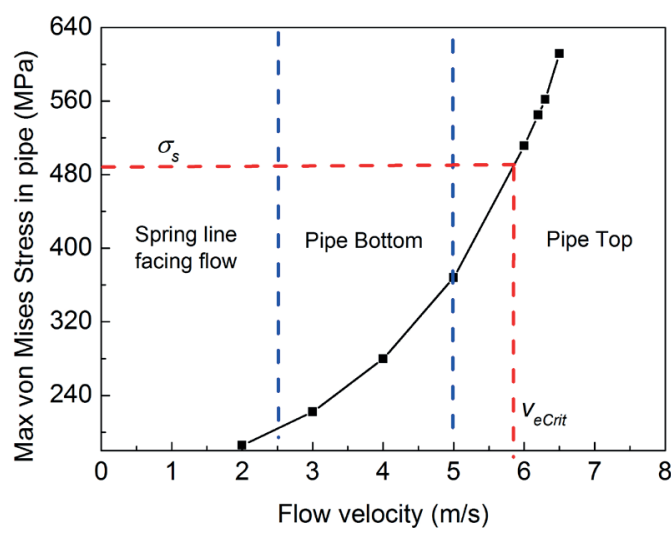

Fig. 15 Trends of max von Mises stress and position in pipe section with flow velocity

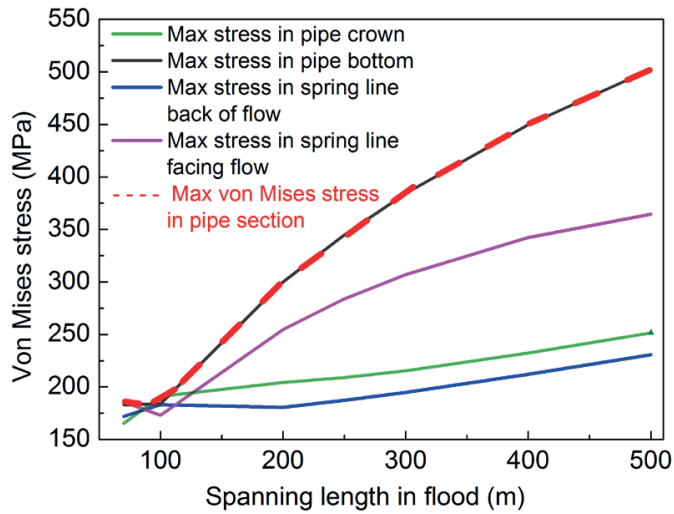

Fig. 16 Trends of maximum stresses in pipe with spanning length in flood

Distributions of maximum von Mises stress in pipe section along pipe axis at various flow velocities were shown in Fig. 14. It shows that, the maximum von Mises stress always appears at the connection point of the bare pipe and pipe with casing, which is caused by the concentrated stress induced by the abrupt variation of pipe bending stiffness. And from Fig. 15 , it can be derived that maximum von Mises stress locates at different positions in pipe section with increase of flow velocity. When flow velocity $v_{e}$ is less than $2.5 \mathrm{~m} / \mathrm{s}$, maximum von Mises stress appears at the spring line facing flow. When flow velocity $v_{e}$ is between $2.5 \mathrm{~m} / \mathrm{s}$ and $5 \mathrm{~m} / \mathrm{s}$, maximum von Mises stress appears at pipe bottom. When flow velocity $v_{e}$ is larger than $5 \mathrm{~m} / \mathrm{s}$, maximum von Mises stress appears at pipe top. When flow velocity $v_{e}$ equals $5.8 \mathrm{~m} / \mathrm{s}$, the maximum von Mises stress reaches yield strength.

\subsection{Critical spanning length for pipe failure}

Under flood erosion, spanning length of pipe may increase. Thus, effect of spanning length on von Mises stress in pipe is also studied. It should be noticed that, in the parametric analysis, length of pipe with casing is fixed, only the bare pipe length is changing.

Fig. 16 shows trends of maximum von Mises stresses at different positions in pipe section with spanning length $L$, among which the maximum von Mises stress in pipe section is the red

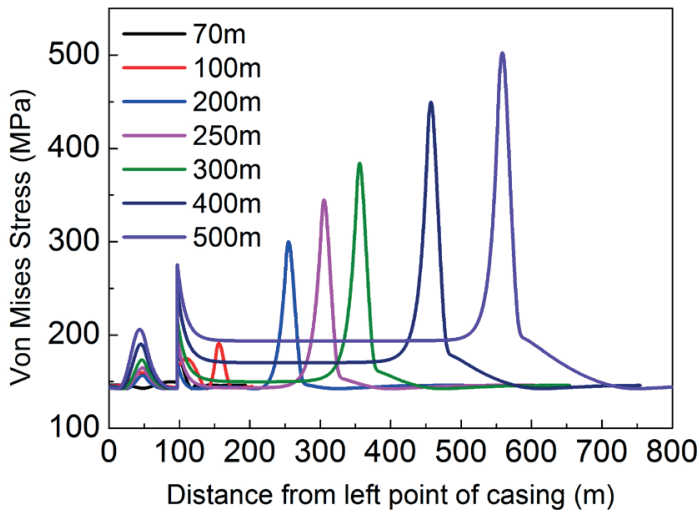

Fig. 17 Distribution of von Mises stress along pipe axis with different spanning length

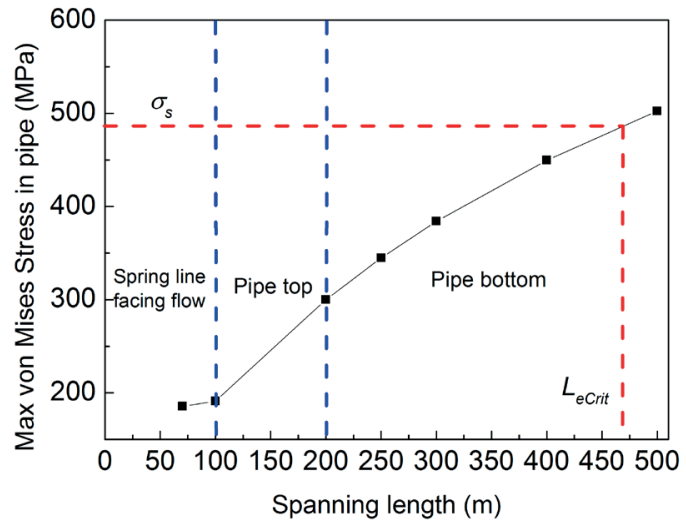

Fig. 18 Trends of maximum von Mises stress and position in pipe section with spanning length

dashed line. Results show that, when $L<100 \mathrm{~m}$, variations of maximum von Mises stress induced by $L$ is small; when $L>100$ $\mathrm{m}$, with increase of $L$, von Mises stresses at all positions in pipe section increase.

Distributions of max von Mises in pipe section along pipe axis with various spanning length were illustrated in Fig. 17. When $L<200 \mathrm{~m}$, the max von Mises stress appears at the connection point of the bare pipe and pipe with casing. In this situation, the max stress is caused by the concentrated stress induced by the abrupt variation of pipe bending stiffness at the connection point. When $L \geq 200 \mathrm{~m}$, the max von Mises stress appears at the supporting point of the bare pipe at riverbed. In this situation, the max stress is caused by the local bending stress induced by soil constraints provided by the right riverbed.

And from Fig. 18, it can be obtained that maximum von Mises stress also locates at different positions in pipe section with increase of spanning length, similar with Fig. 15. When spanning length $L$ is less than $100 \mathrm{~m}$, maximum von Mises stress appears at the spring line facing flow. When the spanning length $L$ is between $100 \mathrm{~m}$ and $200 \mathrm{~m}$, maximum von Mises stress appears at pipe top. When the spanning length $L$ is larger than $200 \mathrm{~m}$, maximum von Mises stress appears at pipe bottom. And the maximum von Mises stress reaches yield strength, when spanning length $L$ equals $467 \mathrm{~m}$. 


\section{Conclusions}

A comprehensive theory and numerical analysis was performed in this study to investigate the stress behavior of a spanning X70 gas pipeline caused by flood erosion. Operating parameters of the gas pipeline and environmental parameters were utilized. A nonlinear finite element model was established with hydrodynamic distribution load applied on spanning pipe and nonlinear soil constraint applied on buried pipe. Increased bending stiffness on pipe structure induced by casing was considered accurately. Special cases of external damage (f.i. collision with floating objects) was ignored in this investigation. A von Mises stress based yield criterion was employed for safety assessment of the pipe, thus plastic deformation was not allowed for the investigated pipe. With the numerical results, some conclusion can be drawn as follows:

1. For the engineering case investigated in this study. Under the monitored flood velocity $(2 \mathrm{~m} / \mathrm{s})$, the maximum von Mises stress in the X70 gas pipe is $185.57 \mathrm{MPa}$, much less than yield strength of X70 line pipe steel (490MPa). The maximum pipe displacement in pipe was just $0.257 \mathrm{~m}$. Thus the pipe is safe at present.

2. The critical flow velocity of the pipe is $5.8 \mathrm{~m} / \mathrm{s}$ with the present spanning length. The failure pipe section is located at the connection point of the bare pipe and the pipe with casing. And the maximum stress appears at pipe top when failure occurs.

3. The critical spanning length of the pipe is $467 \mathrm{~m}$ with the present flow velocity. The failure pipe section is located at the supporting point of the bare pipe on riverbed. And the maximum stress appears at pipe bottom when failure occurs.

\section{Acknowledgement}

The research was financially supported by China National Key Research and Development Project (No. 2016YFC0802105), Natural Science Foundation of China (Grant No. 51779265), Science Foundation of China University of Petroleum, Beijing (Grant No. 2462017BJB10 and No. C201602), the Opening Fund of State Key Laboratory of Ocean Engineering (Shanghai Jiao Tong University) (Grant No. 1314), Opening Fund of State Key Laboratory of Hydraulic Engineering Simulation and Safety (Tianjin University) (Grant No. HESS-1411), Opening Fund of State Key Laboratory of Coastal and Offshore Engineering (Dalian University of Technology) (Grant No. LP1507).

\section{References}

[1] Liu, X. B., Zhang, H., Han, Y. S., Xia, M. Y., Zheng, W. "A semi-empirical model for peak strain prediction of buried X80 steel pipelines under compression and bending at strike-slip fault crossings". Journal of Natural Gas Science and Engineering, 32, pp. 465-475. 2016.

https://doi.org/10.1016/j.jngse.2016.04.054
[2] Wang, X. L., Shuai, J. "Stress analysis of pipeline floating in flood". Gong Cheng Li Xue: Engineering Mechanics, 28(2), pp. 212-216. 2011.

[3] Wang, X., Wang, Z. Y., Han, B. "Mechanical Response Analysis of Pipeline under the Action of Floods". In: ICPTT 2013: Trenchless Technology - The Best Choice for Underground Pipeline Construction and Renewal, Proceedings of the International Conference on Pipelines and Trenchless Technology 2013, pp, 1185-1195. 2013.

https://doi.org/10.1061/9780784413142.124

[4] Chen, Y., Lu, M. X. "The flood suspended span pipeline under load: The numerical simulation study of the sacrifice of safety". Oil and Gas Storage and Transportation, 24(z1), pp. 126-128. 2005.

[5] Li, S. J., Duan, Q. Q, Zhang, H., Wang, J. "Failure analysis of the floating pipeline with defect under flooding load". Engineering Failure Analysis, 77, pp. 65-75. 2017. https://doi.org/10.1016/j.engfailanal.2017.02.011

[6] Ma, T. X., Wu, J. Q., Tang, Y., Hou, H., Li, A, J. "Maximum suspended length of production pipeline". Journal of Southwest Petroleum University: Science and Technology Edition, 34(4), pp. 165-173. 2012.

[7] Yao, A. L., Xu, T. L., Zheng, J., Zeng, X. G., Chen, H. Y. "Study on numerical simulation of critical suspended length of high-pressure gas pipeline crossing riverbed". Engineering Mechanics, 20(3), pp. 152-158. 2013.

[8] Zhang K., Li, Y. P., Han, B., Wang, Z. Y. "Numerical simulation on spanning pipeline's vibration characteristics and safety in flood". In: ICPTT 2013: Trenchless Technology, pp. 986-996. 2013. https://doi.org/10.1061/9780784413142.104

[9] Song, B., Cheng, J. J. R., Chan, D. H., Zhou, J. "Numerical simulation of stress relief of buried pipeline at Pembina River crossing". In: 2006 International Pipeline Conference, Calgary, Alberta, Canada. 25-29 September 2006.

https://doi.org/10.1115/IPC2006-10597

[10] Newmark, N. M., Hall, W. J. "Pipeline design to resist large fault displacement". The US National Conference on Earthquake Engineering. 1975.

[11] Kennedy, R. P., Chow, A. M., Williamson, A. M. "Fault movement effects on buried oil pipeline". Transportation engineering journal of the American Society of Civil Engineers, 103(5), pp. 617-633. 1977.

[12] Karamitros, D. K., Bouckovalas, G. D., Kouretzis, G. P. "Stress analysis of buried steel pipelines at strike-slip fault crossings". Soil Dynamics and Earthquake Engineering, 27(3), pp. 200-211. 2007. https://doi.org/10.1016/j.soildyn.2006.08.001

[13] Karamitros, D. K., Bouckovalas, G. D., Kouretzis, G. P., Gkesouli, V. "An analytical method for strength verification of buried steel pipelines at normal fault crossings". Soil Dynamics and Earthquake Engineering, 31(11), pp. 1452-1464. 2011.

https://doi.org/10.1016/j.soildyn.2011.05.012

[14] Trifonov, O. V., Cherniy, V. P. "A semi-analytical approach to a nonlinear stress--strain analysis of buried steel pipelines crossing active faults". Soil Dynamics and Earthquake Engineering, 30(11), pp. 1298-1308. 2010. https://doi.org/10.1016/j.soildyn.2010.06.002

[15] Trifonov, O. V., Cherniy V. P. "Elastoplastic stress-strain analysis of buried steel pipelines subjected to fault displacements with account for service loads". Soil Dynamics and Earthquake Engineering, 33(1), pp. 54-62. 2012.

https://doi.org/10.1016/j.soildyn.2011.10.001

[16] Zhang, L. S., Zhao, X. B., Yan, X. Z., Yang, X. J. "Elastoplastic analysis of mechanical response of buried pipelines under strike-slip faults". International Journal of Geomechanics, 17(4), pp. 04016109. 2016. https://doi.org/10.1061/(ASCE)GM.1943-5622.0000790 
[17] Zhang, L. S., Xie, Y., Yan, X. Z., Yang, X. J. "An elastoplastic semi-analytical method to analyze the plastic mechanical behavior of buried pipelines under landslides considering operating loads". Journal of Natural Gas Science and Engineering, 28, pp. 121-131. 2016. https://doi.org/10.1016/j.jngse.2015.11.040

[18] Zhang, L. S., Xie, Y., Yan, X. Z., Yang, X. J. "A semi-analytical method of stress-strain analysis of buried steel pipelines under submarine landslides". Applied Ocean Research, 59, pp. 38-52. 2016.

https://doi.org/10.1016/j.apor.2016.05.007

[19] Roudsari, M. T., Samet, S., Nuraie, N, Sohaei, S. "Numerically Based Analysis of Buried GRP Pipelines under Earthquake Wave Propagation and Landslide Effects". Periodica Polytechnica Civil Engineering, 61(2), pp. 292-299. 2017.

https://doi.org/10.3311/PPci.9339

[20] Oskouei, A. G., Asghar, V. O. "The Effect of P-Wave Propagation on the Seismic Behavior of Steel Pipelines". Periodica Polytechnica Civil Engineering, 61(4), pp. 889-903. 2017. https://doi.org/10.3311/PPci.9866

[21] Liu, X. B., Zhang H., Gu, X. T., Chen, Y. F., Xia, M. Y., Wu, K. "Strain demand prediction method for buried X80 steel pipelines crossing obliquereverse faults". Earthquakes and Structures, 12(3), pp. 321-332. 2017. https://doi.org/10.12989/eas.2017.12.3.321

[22] Liu, X. B., Zhang H., Li, M., Xia, M. Y., Zheng, W.,Wu, K., Han, Y. S. "Effects of steel properties on the local buckling response of high strength pipelines subjected to reverse faulting". Journal of Natural Gas Science and Engineering, 33, pp.378-387. 2016.

https://doi.org/10.1016/j.jngse.2016.05.036

[23] Liu, X. B., Zhang H., Han, Y. S., Xia, M. Y., Ji, Y. F. "Numerical and Experimental Study on Critical Crack Tip Opening Displacement of X80 Pipeline Steel". Mechanics, 23(2), pp. 204-208. 2017.

https://doi.org/10.5755/j01.mech.23.2.14535

[24] Liu, X. B., Zhang H., Wu, K., Xia, M. Y., Chen, Y. F., Li, M. "Buckling failure analysis of buried $\mathrm{X} 80$ steel gas pipeline under reverse fault displacement". Engineering Failure Analysis, 77, pp. 50-64. 2017. https://doi.org/10.1016/j.engfailanal.2017.02.019

[25] Saberi, M., Behnamfar, F., Vafaeian, M. "A semi-analytical model for estimating seismic behaviour of buried steel pipes at bend point under propagating waves". Bulletin of Earthquake Engineering, 11(5), pp. 1373-1402. 2013. https://doi.org/10.1007/s10518-013-9430-y

[26] Joshi, S., Prashant, A., Deb, A., Jain, S. K. "Analysis of buried pipelinessubjected to reverse fault motion". Soil Dynamics and Earthquake Engineering, 31(7), pp. 930-940. 2011. https://doi.org/10.1016/j.soildyn.2011.02.003

[27] Uckan, E. B., Anbas, J. S., Wou, R., Paolacci, F., O’Rourke M. J. "A simplified analysis model for determining the seismic response of buried steel pipes at strike-slip fault crossings". Soil Dynamics and Earthquake Engineering, 75, pp. 55-65. 2015. https://doi.org/10.1016/j.soildyn.2015.03.001

[28] Kaya, E. S., Uckan, E., O’Rourke, M. J., Karamanos, S. A., Akbas, B., Cakir, F., Cheng, Y. "Failure analysis of a welded steel pipe at Kullar fault crossing". Engineering Failure Analysis, 71, pp. 43-62. 2017. https://doi.org/10.1016/j.engfailanal.2016.10.004

[29] Melissianos, V. E., Vamvatsikos, D., Gantes, C. J. "Performance Assessment of Buried Pipelines at Fault Crossings". Earthquake Spectra, 33(1), pp. 201-218. 2017. https://doi.org/10.1193/122015EQS187M

[30] Melissianos, V. E., Vamvatsikos, D., Gantes, C. J. "Performance-based assessment of protection measures for buried pipes at strike-slip fault crossings". Soil Dynamics and Earthquake Engineering, 101, pp. 1-11. 2017. https://doi.org/10.1016/j.soildyn.2017.07.004
[31] Kainat, M., Lin, M., Cheng, J. R., Martens, M., Adeeb, S. "Effects of the Initial Geometric Imperfections on the Buckling Behavior of HighStrength UOE Manufactured Steel Pipes". Journal of Pressure Vessel Technology, 138(5), pp. 051206. 2016.

https://doi.org/10.1115/1.4032990

[32] Jalali, H. H., Rofooei, F. R., Attari, N. K. A., Samadian, M. "Experimental and finite element study of the reverse faulting effects on buried continuous steel gas pipelines". Soil Dynamics and Earthquake Engineering, 86, pp. 1-14. 2016.

https://doi.org/10.1016/j.soildyn.2016.04.006

[33] Jalali, H. H., Rofooei, F. R., Attari, N. K. A. "Performance of Buried Gas Distribution Pipelines Subjected to Reverse Fault Movement". Journal of Earthquake Engineering, 10, pp. 1-24. 2017. https://doi.org/10.1080/13632469.2016.1269694

[34] O’Rourke, T. D., Jung, J. K., and Argyrou, C. "Underground pipeline response to earthquake-induced ground deformation". Soil Dynamics and Earthquake Engineering, 91, pp. 272-283. 2016. https://doi.org/10.1016/j.soildyn.2016.09.008

[35] Melissianos, V. E., Korakitis, G. P., Gantes, C. J. Bouckovalas, G. D. "Numerical evaluation of the effectiveness of flexible joints in buried pipelines subjected to strike-slip fault rupture". Soil Dynamics and Earthquake Engineering, 90, pp. 395-410. 2016.

https://doi.org/10.1016/j.soildyn.2016.09.012

[36] Det Norske Veritas. DNV-RP-C205 Environmental conditions and environmental loads. Oslo: Det Norske Veritas, 2007.

[37] ASCE, American Society of Civil Engineers. "Guidelines for the seismic design of oil and gas pipeline systems". Committee on Gas and Liquid Fuel Lifelines of the ASCE Technical Council on Lifeline Earthquake Engineering, Ch. 7, New York. 1984.

[38] American Lifelines Alliance (ALA). "Seismic Guidelines for Water Pipelines". 2005. https://www.americanlifelinesalliance.com/pdf/SeismicGuidelines_WaterPipelines_P1.pdf

[39] O’Rourke, M. J., Liu, X. "Response of buried pipelines subject to earthquake effects". MCEER Monograph No. 3. 1999. http://mceer.buffalo. edu/pdf/report/99-MN03.pdf

[40] Liu, X.B., Zhang, H., Wang, B.D., Xia, M.Y., Wu, K., Zheng, Q., Han, Y.S. "Local Buckling Behavior and Plastic Deformation Capacity of HighStrength Pipe at Strike-Slip Fault Crossing". Metals, 8(1), p. 22. 2018. https://doi.org/10.3390/met8010022

[41] ABAQUS [Computer software]. Hibbitt, Karlsson, \& Sorensen. 